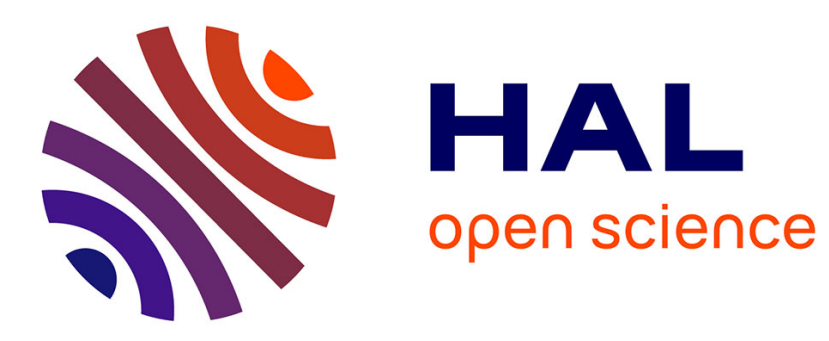

\title{
A design methodology for electrically small superdirective antenna arrays
}

Abdullah Haskou, Ala Sharaiha, Sylvain Collardey, Mélusine Pigeon, Kouroch Mahdjoubi

\section{- To cite this version:}

Abdullah Haskou, Ala Sharaiha, Sylvain Collardey, Mélusine Pigeon, Kouroch Mahdjoubi. A design methodology for electrically small superdirective antenna arrays. Loughborough Antennas and Propagation Conference 2014, Nov 2014, Loughborough University, United Kingdom. pp.405 - 409, 10.1109/LAPC.2014.6996410 . hal-01117301

\section{HAL Id: hal-01117301 https://hal.science/hal-01117301}

Submitted on 16 Feb 2015

HAL is a multi-disciplinary open access archive for the deposit and dissemination of scientific research documents, whether they are published or not. The documents may come from teaching and research institutions in France or abroad, or from public or private research centers.
L'archive ouverte pluridisciplinaire HAL, est destinée au dépôt et à la diffusion de documents scientifiques de niveau recherche, publiés ou non, émanant des établissements d'enseignement et de recherche français ou étrangers, des laboratoires publics ou privés. 


\title{
A Design Methodology for Electrically Small Superdirective Antenna Arrays
}

\author{
Abdullah Haskou, Ala Sharaiha, Sylvain Collardey, Mélusine Pigeon and Kouroch Mahdjoubi \\ IETR UMR CNRS 6164- Université de Rennes 1, Rennes, France \\ abdullah.haskou@univ-rennes1.fr, ala.sharaiha@univ-rennes1.fr, sylvain.collardey@univ-rennes1.fr
}

\begin{abstract}
This paper presents a design methodology for electrically small superdirective antenna arrays. To calculate the required current excitation coefficients the radiated electrical fields obtained from an electromagnetic simulator are integrated in Uzkov equations. The obtained parameters are, then, optimized and used for calculating the power excitation coefficients. The proposed method is deployed for designing a two-element array for an inter-element separating distance varying from $0.05 \lambda$ to $0.5 \lambda$. Simulation results show that the proposed method accurately estimates the required excitation coefficients and the method is validated.
\end{abstract}

Keywords-Superdirectivity, end-fire, excitation coefficients

\section{INTRODUCTION}

The limits on a single antenna- and an antenna array- directivity has undergone a lot of research. R.F. Harrington showed that the directivity of a single antenna can attain $N^{2}+2 N$, $N$ being the highest mode order permitted by this antenna [1]. I. Uzkov demonstrated that the end-fire directivity of $N$ closely placed isotropic radiators can attain $N^{2}$ [2]. Ever since, a lot of study has been done on the design of superdirective antenna arrays [3-6]. E.E. Altshuler et al. studied a threeelement monopole-based superdirective array [3]. O'Donnell and Yaghjian showed that approximately the same directivity obtained with two driven elements can be achieved with exciting one element and shorting the other one [4]. O'Donnell et al. also studied the effect of the frequency optimization on a parasitic two elements array [5]. The authors showed that using the parasitic element as a director can approximately achieve the same results as driving both elements. Sentucq et al. presented a two-element parasitic array [6]. The array is mounted on relatively big ground plane and achieves a maximum directivity of $7.76 \mathrm{dBi}$.

This paper presents a method for designing electrically small superdirective antenna arrays. The proposed method is validated via the design of a miniaturized two-element superdirective antenna array with a separating distance changing form $0.05 \lambda$ to $0.5 \lambda .^{1}$

\section{The Proposed Design Methodology}

The proposed design methodology is as follows:

- $\quad$ First, the antenna array is simulated via an electromagnetic simulator, ANSYS HFSS in our case [7], to obtain the radiated electrical field for each element and the array impedance matrix.

\footnotetext{
${ }^{1}$ This work was supported and funded by the French National Research
} Agency as part of the project "SOCRATE".
- In order to calculate the required current excitation coefficients, the radiated electrical fields are integrated in Uzkov equations that were later re-presented by Altshuler et al in [3]. The current excitation coefficients that maximizes the directivity in the direction $\left(\theta_{0}, \phi_{0}\right)$ are given by:

$$
a_{0 n}=\left[H_{m n}^{*}\right]^{-1} e^{-j k \hat{r_{0}} r_{m}} f_{m}^{*}\left(\theta_{0}, \phi_{0}\right) f_{n}\left(\theta_{0}, \phi_{0}\right)
$$

where $\hat{r_{0}}$ is the unit vector in the far field direction $\left(\theta_{0}, \phi_{0}\right), k=\frac{w}{c}$ is the wave number, and $H_{m n}$ is given by:

$$
\begin{array}{r}
H_{m n}=\frac{1}{4 \pi} \int_{0}^{2 \pi} \int_{0}^{\pi} f_{m}(\theta, \phi) f_{n}^{*}(\theta, \phi) \\
e^{j k \hat{r}\left(r_{m}-r_{n}\right)} \sin (\theta) d \theta d \phi
\end{array}
$$

where $\hat{r}$ is the unit vector in the far field direction $(\theta, \phi)$.

- However, in our case, and since the far field patterns' equations are not known, HFSS results are used instead and the following approximation for $H_{m n}$ is used:

$$
\begin{aligned}
H_{m n}=\frac{1}{4 \pi} \sum_{\theta=0}^{2 \pi} \sum_{\phi=0}^{\pi} f_{m}(\theta, \phi) f_{n}^{*}(\theta, \phi) \\
e^{j k \hat{r}\left(r_{m}-r_{n}\right)} \sin (\theta) \Delta(\theta) \Delta(\phi)
\end{aligned}
$$

where $\Delta(\theta)=\frac{2 \pi}{N_{\theta}}$ and $\Delta(\phi)=\frac{\pi}{N_{\phi}}$ are the far field sampling step in spherical angles $(\theta, \phi), N_{\theta}$ and $N_{\phi}$ being the number of samples.

- It is well known that Equation 2 is the limit of Equation 3 when $\Delta(\theta)$ and $\Delta(\phi)$ tend to zero $\left(N_{\theta}\right.$ and $N_{\phi}$ tend to infinity) [8]. Hence, the obtained parameters need to be slightly modified to maximize the directivity of the array.

- Finally, the current excitation coefficients and the array impedance matrix can be used to calculate the required power excitation coefficients.

\section{Simulation AND RESUlts}

\section{A. Single Element Description}

The single element used in this study is a miniaturized spiral antenna. This antenna is printed on a $0.835 \mathrm{~mm}$-thick FR4 substrate. The antenna total dimensions are approximately $\frac{\lambda}{13} * \frac{\lambda}{23}$. The antenna has a $-10 d B$ bandwidth of approximately $7.3 \mathrm{MHz}$ at a central frequency of $927 \mathrm{MHz}$, and a directivity 
of $2.67 \mathrm{dBi}$. Figure 1(a), shows the antenna geometry and corresponding dimensions. Figure 1(b), shows the antenna simulated input reflection coefficient and Figure 1(c), shows the antenna simulated radiation pattern.

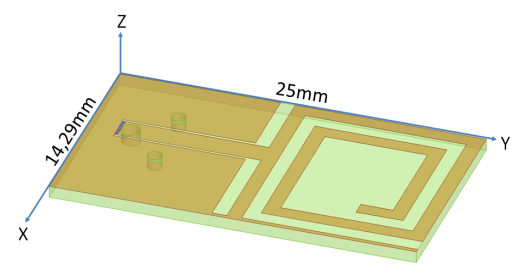

(a)

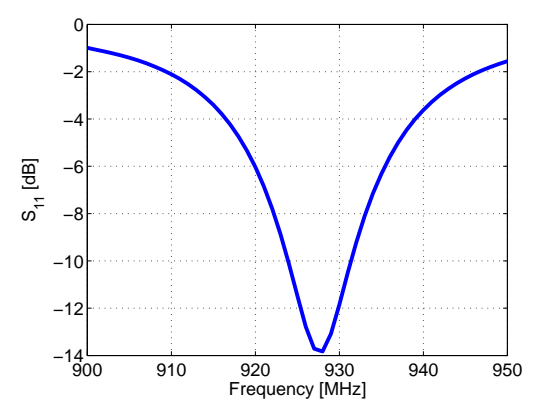

(b)

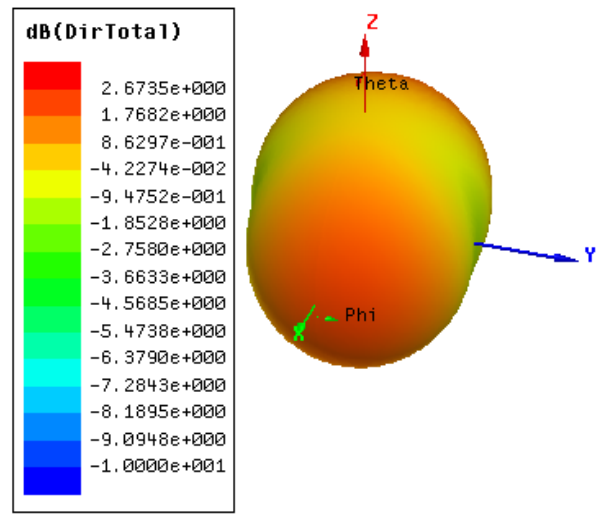

(c)

Fig. 1. Miniaturized spiral antenna. (a) Antenna geometry and dimensions, (b) simulated input reflection coefficient and (c) simulated 3D radiation pattern.

\section{B. Two-Element Array Design}

The proposed method was used to design a two-element spiral antenna array. The separating distance is varied between $0.05 \lambda$ and $0.5 \lambda .^{2}$ Figure 2(a), shows the input reflection coefficient of the two basic elements as a function of the separating distance. Based on this results, the array is designed for a frequency of of $918.75 \mathrm{M} \mathrm{Hz}$ for all the distances. Figure 2(b), shows the initial- and optimized- current magnitudes. The figure shows a significantly good accordance between the initial and optimized magnitudes starting from $0.1 \lambda$. Figure 2(c) shows the initial- and optimized- current phases. The figure shows that as the separating distance increases the estimated phases get closer to the optimal ones. Finally, Figure 2(d) shows the initial- and optimized- end-fire directivity of the antenna array. The figure also shows that as the separating

\footnotetext{
${ }^{2}$ The distance is calculated based on a frequency of $900 \mathrm{MHz}$.
}

distance increases, the obtained directivity approaches the optimal one. The explanation of all the results can be as follows: since the coupling between the two elements increases as the distance decreases, the number of samples for accurately describing the radiated fields increases. Hence, for obtaining the same estimation accuracy, the number of the samples should increase as the separating distance decreases.
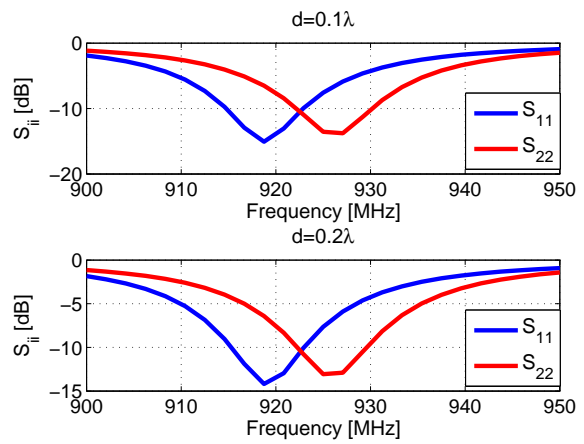

(a)

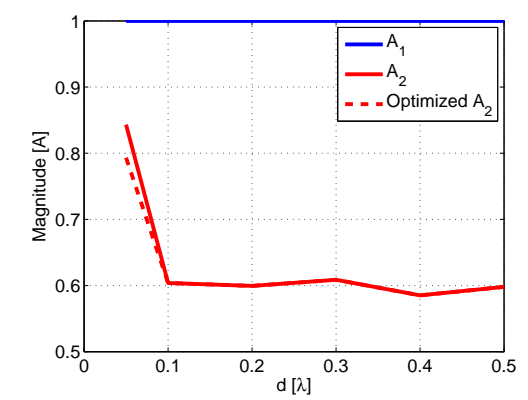

(b)

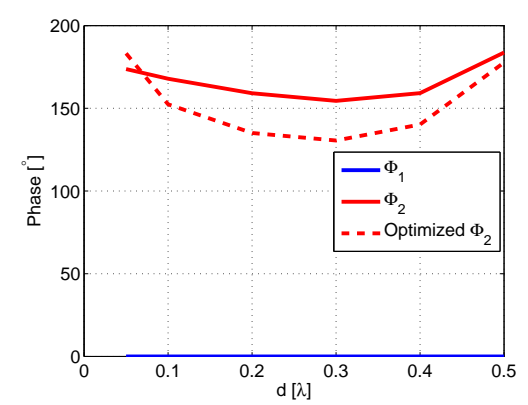

(c)

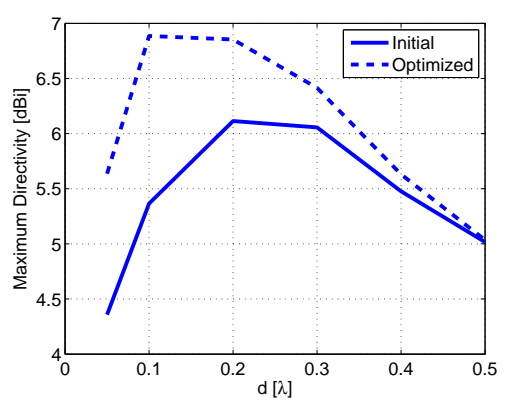

(d)

Fig. 2. Two spirals-based array. (a) The input reflection coefficient of the two elements as a function of the separating distance, (b) current excitation magnitudes, (c) current excitation phases and (d) simulated end-fire directivity. 
Figure 3(a), shows the radiation pattern in the horizontal plane for all the cases. The figure shows that for very small distances, the mutual coupling highly affects the radiation patterns and hence a high directivity cannot be obtained. However, starting from $0.1 \lambda$ a good directivity and Front to Back Ratio (FBR) can be attained, where for $0.1 \lambda$ we have a maximum directivity of $6.89 \mathrm{dBi}$ and a FBR of $8.4 \mathrm{~dB}$. As the distance increases, the backward radiation also increases and for $0.5 \lambda$ the directivity for both end-fire directions is approximately the same. Furthermore, a Maximum to Minimum Ratio (MMR) of about $30 \mathrm{~dB}$ can be noticed for all distances starting from $0.1 \lambda$. Where for $0.1 \lambda$, for example, the side lobe level is $-20.3 d B i$ which means an MMR of $27.2 d B$ (referenced to the maximum of $6.89 \mathrm{dBi}$ ). Figure 3(b) shows the results obtained by applying the calculated power excitation coefficients. The figure shows a very good accordance with the results obtained in the case of exciting the antennas with current signals. The applied power excitations and the maximum achieved directivities are given in Table I. Figure 4 shows the simulated $3 \mathrm{D}$ radiation patterns for a separating distance of $d=0.1 \lambda$ when exciting the array with current and power signals.

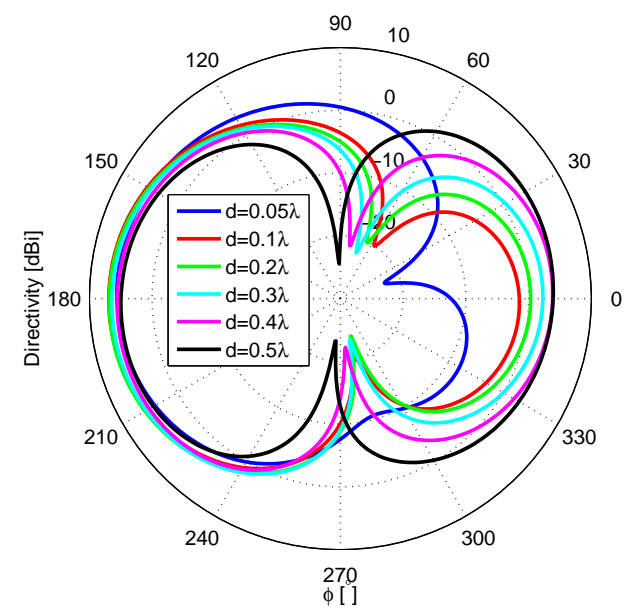

(a)

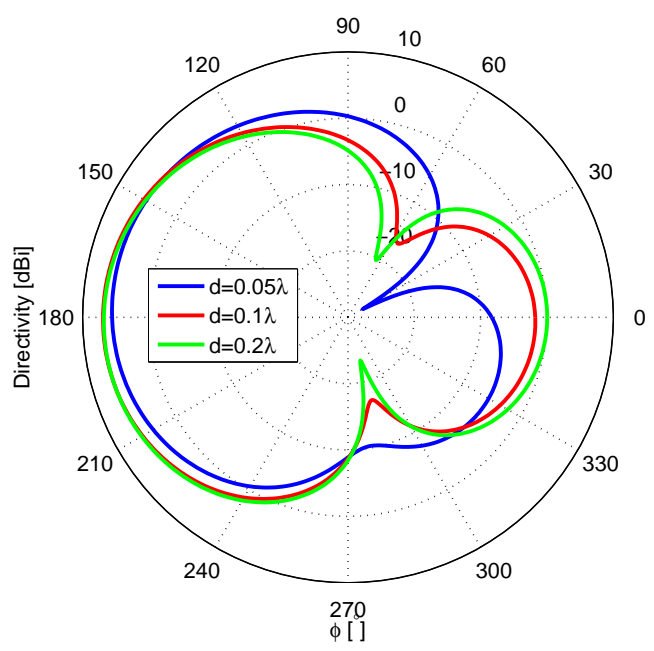

(b)

Fig. 3. Simulated horizontal radiation patterns of a two spirals-based array. (a) With current excitations and (b) with power excitation.
TABLE I. TWO SPIRALS-BASED ARRAY: THE APPLIED POWER EXCITATIONS AND THE ACHIEVED DIRECTIVITY.

\begin{tabular}{|c|c|c|c|c|c|}
\hline$d[\lambda]$ & $P_{1}[W]$ & $\phi_{1}\left[^{\circ}\right]$ & $P_{2}[W]$ & $\phi_{2}\left[^{\circ}\right]$ & $D_{\max }[d B i]$ \\
\hline 0.05 & 1 & 0 & 0.31 & -185.74 & 5.62 \\
\hline 0.1 & 1 & 0 & 0.98 & 130.88 & 6.92 \\
\hline 0.2 & 1 & 0 & 1.22 & 123.33 & 6.82 \\
\hline
\end{tabular}

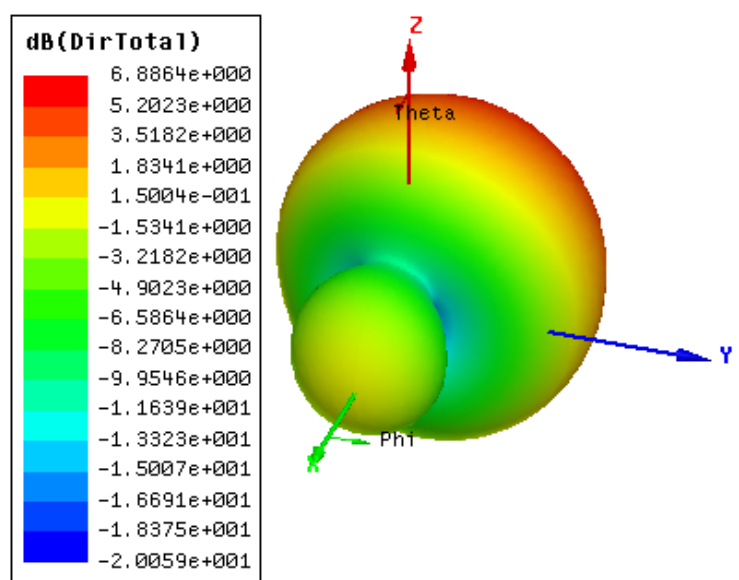

(a)
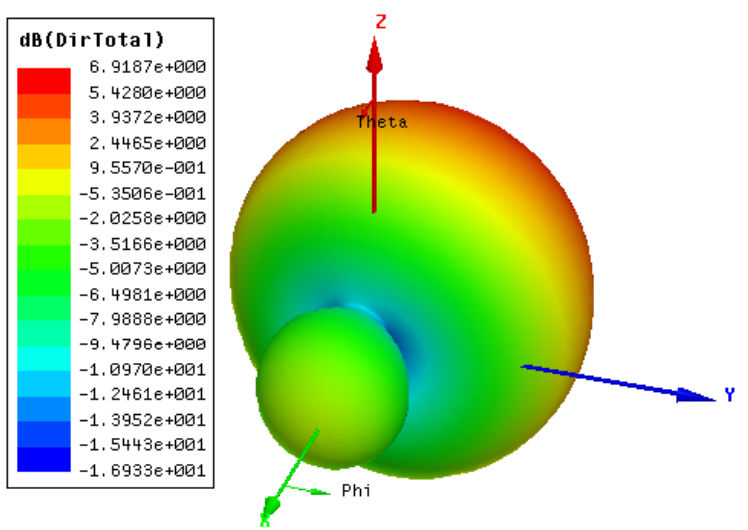

(b)

Fig. 4. Two spirals-based array simulated 3D radiation pattern. (a) With current excitation and (b) with power excitation.

Finally, for a distance of $d=0.05 \lambda$, exciting the first antenna and loading the second one with a capacitor $C=7.19 \mathrm{pF}$, a maximum directivity of $5.67 \mathrm{dBi}$ can be achieved. Figure 5 shows the simulated $3 \mathrm{D}$ radiation patterns for $918.75 \mathrm{M} \mathrm{Hz}$ and the directivity in the direction $(\theta=$ $90, \phi=180)$ as a function of the frequency. The 3D radiation pattern shows a very good accordance with the results obtained when exciting the two antennas with current or power signals. As expected, Figure 5(b) shows that the directivity is maximal at the design frequency and rapidly decreases as we deviate from this frequency. 


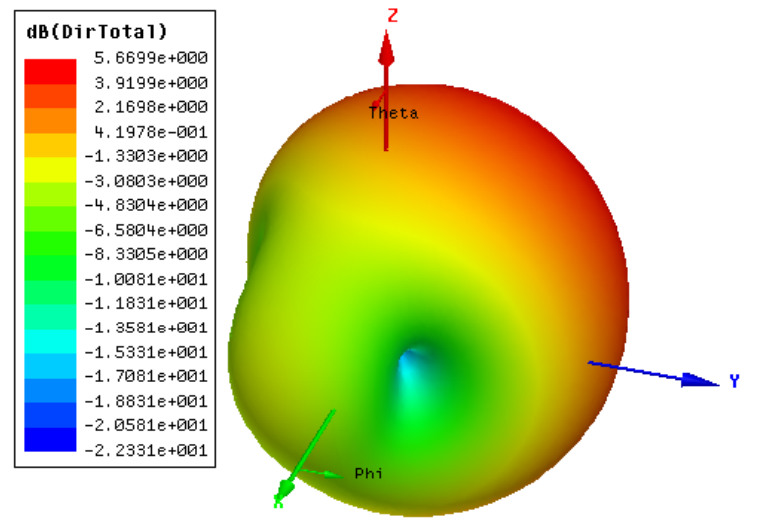

(a)

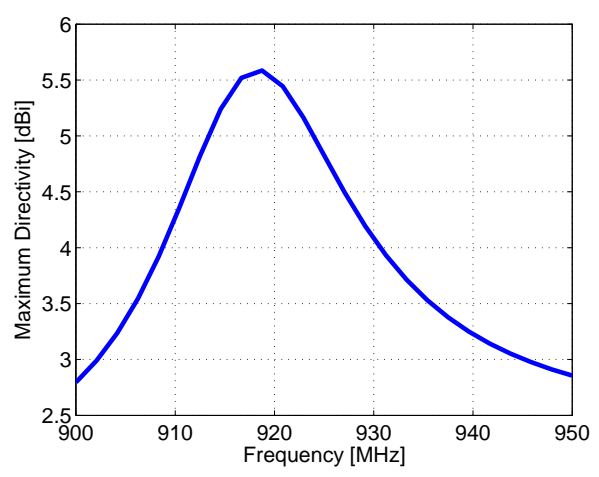

(b)

Fig. 5. Parasitic two spirals-based array. (a) 3D radiation pattern and (b) maximum directivity vs. frequency.

\section{Measurements and Results Validation}

A prototype of the parasitic array was fabricated and measured for the input reflection coefficient and the radiation pattern. Figure 6, shows a photograph of the fabricated prototype. Figure 7, shows the simulated and measured insertion loss and input impedance when taking into account the cable and SMA connector effect. The figure shows a good match between the simulated and measured results. Figure 8, shows the simulated and measured radiation patterns. The figure shows that the superdirectivity effect cannot be monitored because of the cable radiation effect. The figure also shows a considerable difference between the simulated and measured results. This difference can be attributed to the limited length of the cable considered in simulation $(5 \mathrm{~cm})$, while in the measurement set up the cable length which is out of the Teflon is considerably bigger.

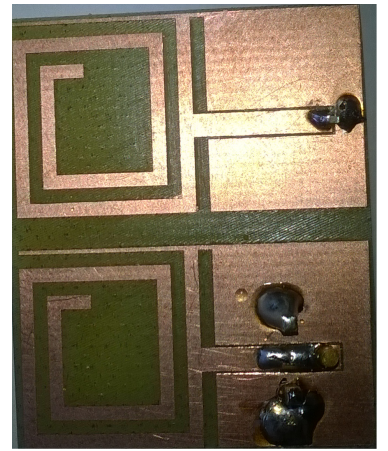

Fig. 6. Two spiral-based array, a photo of the fabricated prototype.

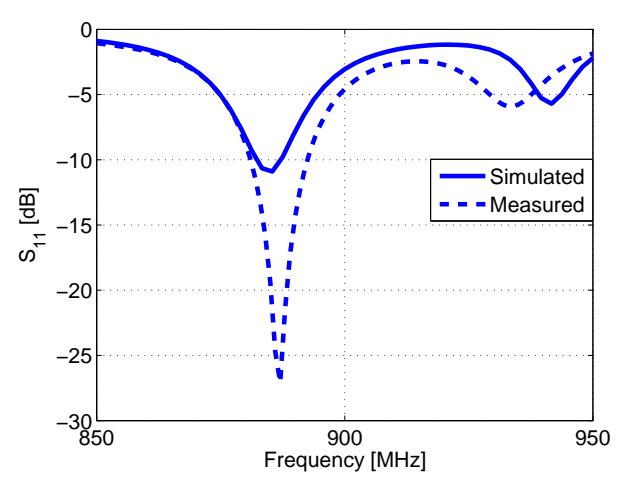

(a)

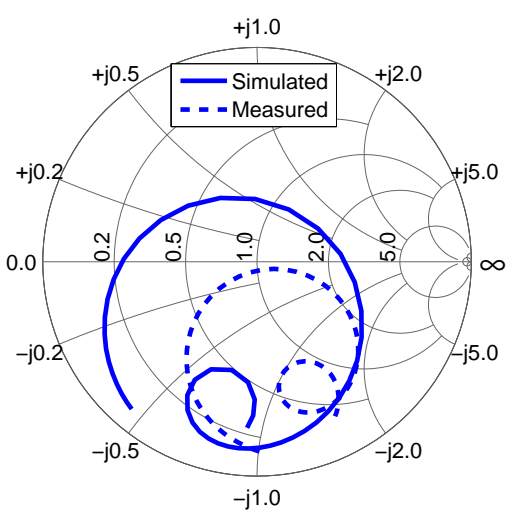

(b)

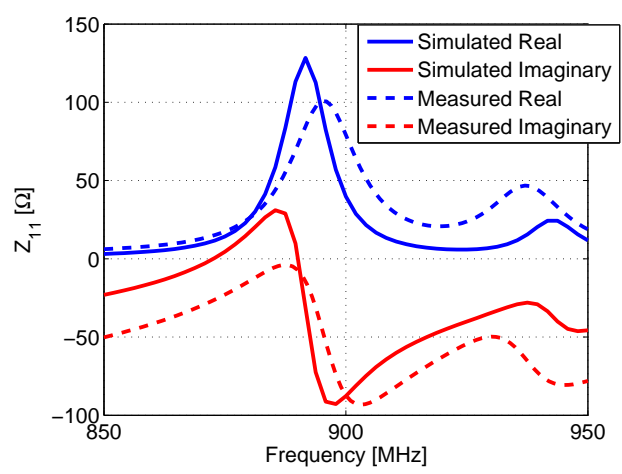

(c)

Fig. 7. Two spiral-based array input parameters measurement results. (a) Insertion loss (b) normalized impedance and (b) impedance. 


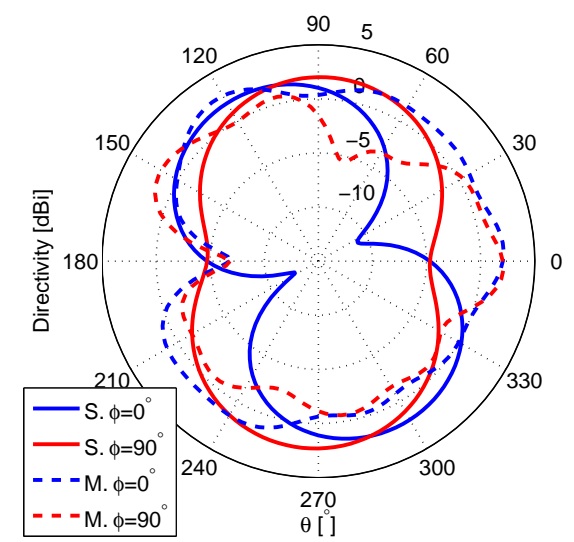

(a)

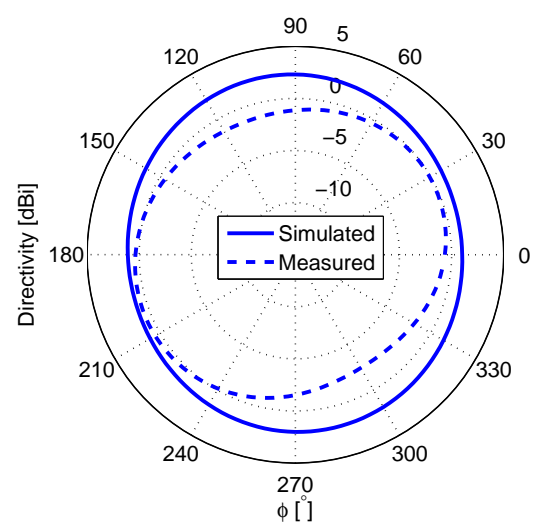

(b)

Fig. 8. Two spiral-based array radiation pattern measurement results. (a) Vertical-plane and (b) horizontal-plane.

\section{CONCLUSION}

In this paper, a method for designing electrically small superdirective antenna arrays is presented. The proposed method is used for designing a two-element array for different separating distances. Simulation results show that the proposed method accurately estimates the required excitation coefficients, and hence, the method is validated. Measurement results for the array input parameters are in a good match with simulated ones.

\section{REFERENCES}

[1] R. F. Harrington, "On the Gain and Beamwidth of Directional Antennas", IRE Transactions on Antennas and Propagation, pp. 219-225, July 1958.

[2] I. Uzkov, "An Approach to the Problem of Optimum Directive Antennae Design", Comptes rendues (Doklady) de l'académie des sciences de l'URSS, Vol. 53, No. 1, 1946.

[3] E. E. Altshuler, T. H. O’Donnell, A.D. Yaghjian, and S. R. Best, "A Monopole Superdirective Array", IEEE Transactions on Antennas and Propagation, Vol. 53, No. 8, pp. 2653-2661, August 2005.

[4] T. H. O'Donnell, and A. D. Yaghjian, "Electrically Small Superdirective Arrays Using Parasitic Elements", IEEE Antennas and Propagation Society International Symposium 2006, pp. 3111,3114, 9-14 July 2006

[5] T. H. O'Donnell, A. D. Yaghjian, and E. E Altshuler, "Frequency Optimization of Parasitic Superdirective Two Element Arrays", IEEE Antennas and Propagation Society International Symposium 2007, pp. 3932,3935, 9-15 June 2007.
[6] B. Sentucq, A. Sharaiha, and S. Collardey, "Superdirective Compact Parasitic Array of Metamaterial-Inspired Electrically Small Antenna", International Workshop on Antenna Technology (iWAT), pp. 269,272, 4-6 March 2013.

[7] ANSYS HFSS, Pittsburg, PA 15219, USA.

[8] B. Riemann, "Ueber die Darstellbarkeit einer Function durch eine trigonometrische Reihe", Göttingen: Dieterich, 1867. Online version available at: (http://eudml.org/doc/203787). 